\title{
Allocating pupils to their nearest school: the consequences for ability and social stratification
}

\author{
Rebecca Allen (r.allen@ioe.ac.uk) \\ Institute of Education, University of London
}

Paper published as:

Allen(2007) 'Allocating pupils to their nearest school: the consequences for ability and social stratification'. Urban Studies. Vol. 44(4) pp. 751-770 


\begin{abstract}
This study examines the proposition that secondary school choice in England has produced a stratified education system, compared with a counterfactual world where pupils are allocated into schools based strictly on proximity via a simulation that exploits the availability of pupil postcodes in the National Pupil Database. The study finds current levels of sorting in the English secondary school system - defined as pupils who do not attend their proximity allocation school - to be around 50 per cent, but estimates that only one-in-five pupils are potentially active in sorting between non-faith comprehensive schools. School segregation is almost always lower in the proximity counterfactual than in the actual data, confirming that where pupils are sorting themselves into a non-proximity school, it does tend to increase social and ability segregation. The difference between school and residential segregation is greatest in urban areas and LEAs with many pupils in grammar and voluntary-aided schools.
\end{abstract}

\title{
Background
}

Government policies, introduced from 1988 onwards, that seek to influence the allocation of pupils to secondary schools in England are among the most contentious aspects of education policy today. These policies introduced a 'quasi-market' (Glennerster, 1991) for schools in England by increasing the 
ability of parents to exercise choice and giving more schools control over their admissions criteria. The policies, all of which weaken the link between place of residence and school attended, were introduced as a route to improving standards by increasing the autonomy of schools and encouraging competition for pupils via parental choice.

Research has not been able to show how much these policies have systematically altered the allocation of pupils to schools in Local Education Authorities (LEAs) across England. This study addresses this question by comparing the current allocation of pupils to schools to a simulation where pupils are allocated into schools based strictly on proximity, while maintaining current school capacities. This is possible with the availability of pupil postcodes (zip codes), collected annually from schools since 2001. The extent to which pupils do not attend their proximity school measures current pupil mobility, which indicates the potential extent of choice exercised by parents. The simulation also helps us understand how this pupil mobility affects the stratification of pupils across schools.

Prior to 1988 , LEAs had a duty to have regard to the general principle that children should be educated according to the wishes of parents under Section 76 of the Butler Education Act of 1944, but this was a weak directive given the concurrent requirement to use resources efficiently (Fitz et al., 2001). Though some English LEAs introduced parental choice much earlier, the 1980 Education Act and 1988 Education Reform Act enshrined 
the parental right to exercise a preference for a particular school. The introduction of locally assessed admissions numbers for each school's enrolment meant that LEAs could no longer refuse to meet preferences for particular schools unless that number of places had been filled and it is now easier for schools to expand capacity (though only 120 secondary schools have since 1999 (Select Committee for Education \& Skills, 2005)).

The quasi-market enabled schools to opt out of LEA control and institute autonomous admissions procedures and budgets by becoming Grant Maintained (GM) schools (most of which later became foundation schools), with some introducing partial ability selection. $30 \%$ of schools now determine their own admissions, compared to $15 \%$ in 1988 (West \& Pennell, 2003). The Specialist Schools programme reinforced the rationale of parental choice by encouraging diversity of schools, and again these schools were able to select $10 \%$ of pupils by aptitude. Though catchment areas or distance to school oversubscription criteria have roles of continuing significance in most of the country (Jowett, 1995; Mayet, 1996), the quasimarket for school places in England, rightly or wrongly, became associated with schools choosing pupils as much as parents choosing schools.

The principal concern for critics of the school choice policies is that they may be inequitable and lead to increasing school stratification (defined as the unevenness in the distribution of pupils of certain characteristics across schools), for two reasons. First, competition gives schools an incentive to 
boost their league table position by selecting, or 'cream-skimming', pupils on the basis of ability or covert social criteria. West et al.'s (2004) analysis of comprehensive secondary school admissions criteria in England reveals a significant minority of (mostly voluntary-aided and foundation) schools using criteria which appear to be designed to select a certain group of pupils and so exclude others:

- Admissions criteria relating to ability/aptitude were mentioned by $11.2 \%$ of foundation schools, $6.5 \%$ of voluntary-aided schools and $0.3 \%$ of community schools.

- Ability banding by schools for selection purposes was found to be more prevalent in voluntary-aided / foundation schools (5\%) than community schools (2\%), with evidence of uneven bands being used by some schools, which allow higher abilities to be over-represented.

- $13 \%$ of schools (92\% of voluntary-aided schools) in West et al.'s sample used religious criteria to admit pupils; some used interviews to 'assess religious or denomination commitment' (DfEE, 1999), which can be used as a device for covert cream-skimming.

The second argument why choice might increase school stratification is that families of lower socio-economic backgrounds will be disadvantaged in their ability to access the 'best' schools; this may be for reasons of financial or time constraint, or they may lack the information to employ a successful 
school choice strategy. There are now a large number of research studies across many countries concluding that there is a strong association between social class and school choice (e.g. Gewirtz et al., 1995; Hastings et al., 2005; Waslander \& Thrupp, 1995; Zanten, 1996). There are many wellfounded explanations for this association which are not explored further in this paper. Crucially though, there is evidence that parents tend to consider the 'best' schools to be those with a high mean pupil ability and socioeconomic status (e.g. Ladd, 2002; Willms \& Echols, 1992). This strategy appears rational, not least because the ability of peers influences individual pupil attainment (Feinstein \& Symons, 1999; Robertson \& Symons, 2003; Zimmer \& Toma, 2000), and suggests that those who successfully elect not to attend their neighbourhood school will be attempting to access a superior peer group.

The question of whether school choice policies in England have increased stratification between schools is an empirical question; but the gradual introduction of the policies on a national basis and the lack of historical pupil-level data have made it difficult to use simple longitudinal or crosssectional comparisons to measure a causal relationship between policy implementation and school stratification. Based on current evidence, it is not possible to argue that the average level of school segregation in an LEA has substantially risen, or indeed fallen, since 1988 (Allen \& Vignoles, 2006; Goldstein \& Noden, 2003; Gorard et al., 2003; Noden, 2000). 
However, there is clearer evidence that grammar schools and ownadmissions authority schools are associated with greater levels of school segregation, measured using free school meals eligibility as an indicator of low income (Allen \& Vignoles, 2006; Goldstein \& Noden, 2003; Gorard et al., 2003). More significantly, two studies have now shown that LEAs with a greater proportion of pupils in voluntary-aided schools have experienced greater growth in segregation between 1994 and 1999 (Goldstein \& Noden, 2003) and between 1999 and 2004 (Allen \& Vignoles, 2006). Goldstein and Noden find a similar pattern for foundation and grammar schools; Allen and Vignoles (using the later data) do not.

Because this study compares school segregation to a counterfactual proximity allocation of pupils, it is similar in its strengths and limitations to Burgess et al. (2006). They try to explain why the magnitude of the difference between residential and school segregation ("post-residential sorting') differs substantially between LEAs. This study moves beyond the scope of their work by analysing the role of own-admissions authority schools in contributing to sorting and also overcomes important methodological concerns regarding a random allocation bias on their measure of post-residential sorting (discussion in the method section).

Unfortunately, the simulated proximity allocation used in this study, while insightful in certain respects, is a poor proxy for the real world experiment for one principal reason: if we abandoned school choice and non-proximity 
admissions criteria in England today, we would expect some reallocation in the housing market as parents move house to attempt to achieve their desired choice of school. In other words, residential levels of segregation are endogenous to the policies under examination in this study. Empirical studies in the US and UK have shown that good schools do cause house prices to rise, (Black, 1999; Gibbons \& Machin, 2003, 2006; Leech \& Campos, 2001), but no estimates exist as to the size of the endogeneity bias on residential segregation in our data. Specifically, it is not clear the extent to which school choice reduces the need of parents to locate close to a good school, given the outcome of the English school choice process is highly uncertain for a family. This means that when an association between a policy and the size of post-residential sorting is measured, we can go no further than infer that the policy has increased school segregation or reduced residential segregation (or both).

\section{Data}

Data for English school pupils is drawn from the National Pupil Database (NPD). This combines attainment data for pupils in Key Stage tests at ages $7,11,14$ and 16 with a limited range of pupil characteristics, collected from schools in January each year. The 463,117 pupils in this analysis were in year 9 (age 13/14) in 2002/3. Using a cohort in year 9 (rather than year 7) has the advantages that it means every student in England will have 
completed the secondary admissions process, ${ }^{1}$ though there is a risk that the pupil has moved house since year 7 so the postcode used in this study will not relate to residential location at the point choice was made. Though the dataset could be considered to be a population rather than a sample, certain pupils do not form part of this study (namely those at private schools, special schools, hospital schools, detention centres, all boarders, pupils on the Isles of Scilly and Isle of Wight). Key descriptors of all variables used in this study are in Table 1.

The main drawback of using NPD is that it does not provide a good indicator of the socio-economic status of the child, so this study relies on eligibility for free school meals (FSM) as an indicator of low income. ${ }^{2}$ Richer geo-demographic data such as Indices of Multiple Deprivation and Acorn household type indicators are available via the pupil postcode in NPD, but these refer to the average characteristics of the street or area and not the family characteristics directly, which renders them unusable for this study. For example, the presence of a faith school in a town might allow a church-going family to purchase a less expensive house in the catchment area for a community school with a deprived intake, knowing that their children would attend the faith school. Geo-demographic data is therefore likely to systematically underestimate the socio-economic characteristics of this family, thus biasing all parameters of interest in this particular study. The pupil prior attainment (known as 'ability' in this study) variable is 
constructed from the average Key Stage 2 (KS2) mark of the child in maths, English and science. Pupils sit these tests in primary school at age 11, so scores are independent of secondary school effectiveness. Documentation of the construction of this continuous variable (where marks are recalibrated as fractional equivalents of levels) can be found in Levačić et al (2005). Binary indicators for whether a pupil is in the top quintile by ability and lowest quintile by ability are also used.

Pupil and school postcodes are used to place each pupil's school and home address on an OS grid location to within 1 metre of the mean postcode position and within 100 metres of the pupil's home address. The neighbourhood that the pupil lives in is identified by the nested statistical areas known as Middle Super-Output-Areas (SOAs), Lower SOAs and Output-Areas (OAs). Middle SOAs contain an average of 78 Year 9 pupils; Lower SOAs contain an average of 17 Year 9 pupils; and OAs contain an average of less than 4 Year 9 pupils. These SOAs are intended to contain an approximately equal number of pupils, which makes them superior to administrative boundaries such as wards.

The 3,071 schools in the dataset are identified by whether they are a grammar, foundation (non-grammar and including City Technology Colleges), voluntary-aided (VA) (non-grammar) or single sex school. The default school is a Community (LEA controlled) comprehensive school. ${ }^{3}$ VA schools are usually owned by churches (two-thirds of which are Roman 
Catholic), and control their own admissions criteria; foundation schools are usually owned by their governing bodies, again controlling their own admissions criteria.

LEA-level data from the 2001 census is used to calculate the population density of the area, the proportion of families that are lone parent households and the proportion of families where no parent is employed. Other census indicators for skills levels in the area were tested but not used in the final analysis.

Insert table 1 about here

\section{Method}

\section{A counterfactual to current school admissions}

The policies we label as 'school choice' policies in the UK are all intended to reduce the strength of the relationship between place of residence and school attended. Therefore, one possible counterfactual to these policies is the administrative allocation of pupils to school based solely on a proximity admissions criterion. This study tests two key propositions. First, that the amount of pupil mobility in an LEA depends on the ability of parents to access a non-proximity school. This in turn is related to: ${ }^{4}$ 
- population density in the LEA, which indicates the size of the potential choice set for parents; ${ }^{5}$

- the proportion of lone parent families and families where no one works in the household;

- the proportion of schools in the LEA who may be using nonproximity oversubscription criteria, i.e. grammar, VA (nongrammar) and foundation (non-grammar) schools.

Second, that the difference in the level of current school segregation relative to segregation under the proximity allocation will be greatest where grammar, VA and foundation schools exist. This may be because oversubscription criteria at these schools tend to favour higher income or ability pupils. Alternatively, this may be because school choice strategies differ by social background of family.

If this second proposition holds, we can then infer that the potential to reduce school stratification via a policy intervention that institutes a strict proximity policy is greatest in areas with many grammar, VA and foundation schools. However, we must accept that residential sorting may rise in response; therefore gains in school integration may represent an upper bound. 
The proximity counterfactual is created by computer using the OS grid references for pupil and school addresses in the dataset using the following rules:

1. all schools must fill their places on the basis of proximity, with a strict preference for pupils who live closer to the school. All other school admissions criteria at schools are removed (though single sex schools remain single sex $)^{6}$

2. school capacity is set as either the current official school capacity or the size of the current pupil intake, whichever is greater; ${ }^{7}$

3. no parents will be allowed to exercise choice to attend another school, even if that school has spare capacity; ${ }^{8}$

The simulation presented in this report is a two-sided Priority Matching Mechanism (see Roth, 1984, for more details): ${ }^{10}$

1. The first round identifies each pupil's nearest school and distance from home and pupils are allocated to it, provided that there is enough spare capacity for them. If there are more pupils for whom it is the nearest school than there are places available, only those nearest are allocated.

2. At the end of the first round, $84 \%$ of pupils have been allocated to their nearest school. 1,271 of the 3,071 schools (41\%) are full to capacity and will therefore be excluded from future iterations. 
3. The second round is similar, but with fewer spare places left at schools and only $16 \%$ of pupils. The nearest school for each unplaced pupil - out of the schools with remaining space - is identified. Again, pupils are allocated to the nearest school if there is enough space to accommodate them, with priority given in strict order of proximity.

The process must be repeated 9 times to allocate all pupils to a school. At the end of the process there are still 33,845 empty spaces at schools ( $7 \%$ of all places available at the start of the allocation) because there is spare capacity in the system. Table 2 summarises the key details of distances travelled by pupils who are allocated at each stage of the procedure.

Insert table 2 about here

The simulation does not intend to replicate a real-world situation since this type of strict proximity allocation - without, for example, grammar schools and church schools - has never existed in England. Even where proximity is now the over-riding allocation principle in an area, many LEAs continue to use catchment areas to aid planning and certainty of the allocation process for parents. It is simply suggested that this simulation provides a valid mechanism for examining the stratification implications of current student 
sorting. This claim is made on the basis that only a tiny proportion of the 463,117 pupils are required to make unreasonable journeys in the allocation. $^{11}$

Given that almost all grammar and VA schools existed prior to the 1980s, two additional simulations are used to provide a better indication of the possible role of 'new choice' or post-1988 policies in changing pupil sorting. The three simulations are referred to as:

Proximity I: the proximity allocation where no schools retain current pupils (this is the principal simulation and is described above).

Proximity II: a proximity allocation where grammar schools retain current pupils (to generate an estimate of between-comprehensive pupil sorting).

Proximity III: a proximity allocation where grammar and VA schools retain current pupils (to generate an estimate of between non-faith comprehensive pupil sorting).

\section{Measuring differences in segregation}

Since the outcome of interest in this study is the stratification of a local education market under different scenarios, it is necessary to geographically define the market. This study principally relies on LEAs as the area of 
analysis, despite the high levels of cross-LEA movement between certain LEAs, particularly those in London. The simulation allows pupils to attend their nearest school, even if it is in a different LEA to their home or current school. However, the measurement of LEA-level segregation in the actual data versus the proximity allocation will often involve slightly different sets of pupils. ${ }^{12}$

Segregation (i.e. the numerical measure of the stratification between two groups) between schools in an LEA is measured using the index of dissimilarity (D). In the context of segregation between schools by free school meal eligibility, measured at LEA level, the formula for D is:

$$
D=\frac{1}{2} \sum_{i=1}^{I}\left|\frac{f_{s m_{i}}}{F S M}-\frac{\text { nonfsm }_{i}}{\text { NONFSM }}\right|
$$

where there are I schools in the LEA;

school i has $f_{s m}$ pupils eligible for free school meals and nonfsm ${ }_{i}$ pupils who are not eligible for free school meals.

In the LEA as a whole, FSM pupils are eligible for free school meals and NONFSM pupils are not eligible for free school meals.

Segregation by FSM eligibility, by top $20 \%$ ability and by the lowest $20 \%$ ability is measured using D. In addition the intra-class correlation (ICC) of a continuous measure of KS2 ability between-schools in an LEA is used as a further estimate of segregation, where ICC $=1$ indicates that schools are fully stratified because there is no within-school variation in ability and ICC $=0$ indicates that schools are fully integrated by ability because there is no between-school variation in ability. 
This study seeks to account for differences in the level of actual segregation between schools, seg ${ }^{\text {real }}$, versus the level of segregation under the proximity allocation, seg ${ }^{\text {prox I }}$. It is hypothesised that the size of this difference will relate to the level of pupil mobility (i.e. the proportion of pupils who are not currently educated in their proximity allocation school) in LEA i, but also structural features of the quasi-market:

$\operatorname{seg}_{i}^{\text {real }}-\operatorname{seg}_{i}^{\text {proxI }}=\beta_{0 i}+\beta_{1 i}$ mobility $_{i}+\varepsilon_{i}$

$\operatorname{seg}_{i}^{\text {real }}-\operatorname{seg}_{i}^{\text {proxI }}=\beta_{0 i}+\beta_{1 i}$ popdensity $_{i}+\beta_{2 i}$ grammar $_{i}+\beta_{3 i} V A_{i}+\beta_{4 i}$ foundation $_{i}+\varepsilon_{i}$

Given the segregation index is $0-1$ bounded, there is no clear a priori reason to favour the measurement of post-residential sorting as the absolute difference in the value of the segregation indices $\left(\mathrm{seg}^{\text {real }}-\operatorname{seg}^{\text {prox I }}\right.$ ) over the proportionate difference in the value of the segregation indices $\left(\mathrm{seg}^{\text {real } /}\right.$ $\operatorname{seg}^{\text {prox I}}$ ). The rank of LEAs on both the absolute and proportionate measures of post-residential sorting will be sensitive to the segregation index chosen. So, both are tested and the absolute difference is selected on the basis that it provides more consistent regression results.

The properties of $\mathrm{D}$ and the rationale for its use can be found elsewhere (e.g. Allen \& Vignoles, 2006), but there are two properties that are highly relevant to its use as a dependent variable in a regression and therefore warrant mention here. First, D incorporates a linear payoff criterion to unevenness in the distribution of FSM pupils across schools (Zoloth, 1976). 
If we believe that the effects on social welfare of schools' having different FSM proportions are non-linear, then D can provide us a broadly acceptable ordinal ranking of segregation but an inappropriate cardinal measurement of amounts of segregation. The robustness of results to this issue can be mitigated to some extent by replication of results using an index, such as the Square Root index (Hutchens, 2004), with a highly non-linear payoff criterion. These robustness tests are not reported in this paper, but are available from the author.

A second issue is that the value of segregation under a random allocation of pupils to schools will be significantly greater than zero because a single school cohort is quite small, and this is generally an issue where a segregation index is used as the dependent variable in a regression (Carrington and Troske, 1997). This is known as the 'random allocation bias', the size of which is a function of the size of the LEA, the number of schools in the LEA and the overall FSM proportion in the LEA (Cortese $e t$ al., 1976). Randomisation tests (available from author) show that the variation is the size of the random allocation bias between LEAs is substantial in all single cohort NPD datasets and therefore potentially invalidates all existing NPD segregation research that cannot account for this. The random allocation bias is overcome in the specifications described above because the size of the bias will be almost identical for $\operatorname{seg}^{\text {real }}$ and $\operatorname{seg}^{\text {prox I }}$ (since their margins should be approximately the same in the LEA), 
thus removing the influence of the bias on the dependent variable seg ${ }^{\text {real }}$ $\operatorname{seg}^{\text {prox I }}$.

\section{Results}

\section{The level of pupil mobility in LEAs}

The term mobility in this analysis means the extent to which pupils attend a different school to their current school in the proximity allocation. If the year 9 pupils in this simulation were re-allocated to schools on the basis of strict proximity, $52 \%$ of pupils would be placed in a different school to their current school. This is consistent with Burgess et al.'s (2006) indication that approximately half of all pupils currently attend their nearest school. The median pupil's distance to school under a proximity allocation would be just $64 \%$ of the length of their current journey.

Levels of pupil mobility differ substantially by LEA, as shown in Figure 1. Not surprisingly, high mobility LEAs are largely located in or around London, with $86 \%$ of pupils in Lambeth schools, for example, not attending the school they would be under the proximity allocation. Manchester, Liverpool and Birmingham also have high levels of pupil mobility. By contrast, areas where very little pupil mobility currently appears to be exercised are more rural, for example Leicestershire (mobility $=15 \%)$, East Riding of Yorkshire (23\%), Rutland (24\%) and Cambridgeshire (27\%). 
Table 3 shows the estimates from the regression to test whether pupil mobility in an LEA is associated with particular school or population characteristics. The overall model explains $75 \%$ of the between-LEA variability in the proportion of pupils who are not at their proximity school; population density and all school type variables are significant at $1 \%$. The size of the effect of grammar schools and VA schools is approximately the same, which is logical since neither tends give priority to pupils on the basis of proximity. Though the foundation school coefficient is significant, the size of the effect on pupil mobility is very small: if $25 \%$ of pupils in an LEA are at foundation schools, mobility would be estimated to increase by just 2.5 percentage points. The effect of population density is so strong that an urban LEA with only community comprehensives might have higher pupil mobility than a very rural area with grammar schools.

Insert table 3 about here

Fifty-two percent of pupils do not attend their proximity school, yet figure 2 uses additional simulations and analysis of the pupil's neighbourhood to 
establish that the destinations of only around one in five pupils might have been affected by post-1988 choice policies (this estimate ignores the possibility that changes in capacity at schools have altered the 'neighbourhood' school for some pupils). It estimates this because many of these 'sorting' pupils are at grammar or VA schools or are likely to be at the de facto neighbourhood school, but this is not identified by the simulations.

\section{Insert figure 2 about here}

15 percent of pupils in England are attending a grammar (3\%) or VA school (12\%), and this is not their proximity school. 6 percent of pupils attend their proximity non-faith comprehensive (or secondary modern) school, i.e. the proximity school in Proximity I is actually a grammar or VA school. 5 percent of pupils are attending the same school as the majority of pupils living in their Middle SOA (or neighbourhood). We can assert that these pupils are highly likely to be attending a designated catchment area school, or they are attending a school under a proximity criterion. An additional 4 percent of pupils are probably at their school on the basis of catchment/proximity criterion because they attend the same school as the majority of pupils in the Lower SOA where they live. Since the Lower SOA is smaller than the Middle SOA, this identifies a set of pupils where 
the Middle SOA is crossing the catchment boundaries for more than one school. However, the use of the lower SOA (which is a small area so can have a homogenous social mix) presents a risk of mis-classification of pupils, so it might be the case that all the pupils in the SOA are successfully 'exercising choice' to attend a school far away from their homes.

This analysis shows us that more than half the pupils who are not attending their proximity school are either highly likely to be at a neighbourhood school or they are 'choosing' not to based on criteria available to parents before 1988 (i.e. grammar and faith schools). Whereas Burgess et al. (2006) suggested that there is a high level of choice in England because $50 \%$ of pupils are not at their nearest school, this research places an upper bound on pupil mobility due to the new choice policies of $22 \%$. This appears to be more in-line with the only existing study to model exact catchment areas, which found pupil mobility of around one-third in an LEA with some grammar schools (Parsons et al., 2000).

Unfortunately, this analysis allows us to do no more than speculate about why the remaining $22 \%$ of pupils are not at their proximity school. These pupils are more likely to live in London (where they make up 34\% of all London pupils) and are not, on average, attending schools with a superior social mix or ability of intake to their proximity allocation school. We can 
hypothesise that these 103,223 pupils are not at their proximity school for the following reasons:

1. Edge of catchment. Some pupils are attending the same school as pupils in the neighbourhood, but the SOA categories could not identify this (for example, because catchment boundaries cross the SOA). Half of these unaccounted for pupils are attending the same school as over $50 \%$ of pupils in the Output Area (but this statistical area is very small, so we cannot be certain that it is a neighbourhood school).

2. Family relocation. Some pupils may have gained their place at the school on the basis of a sibling policy, where other members of the family were allocated a proximity place because the family used to live the area. Alternatively, the family may have moved house since gaining a proximity place in Year 7.

3. LEA-wide ability banding. Some pupils are attending a school on the basis of a banding system in an LEA or school: this may, or may not be, their first choice school. The four London LEAs who were operating LEA banding at the time these pupils entered secondary school do have relatively high degrees of unexplained mobility.

4. Choice without displacement. Some pupils are exercising choice to attend a school other than the proximity school, and have gained a 
place at their chosen school via a proximity criterion (or other means) because all pupils who live closer either gained a place at the school or did not wish to attend it.

5. Choice with displacement. Some pupils have successfully exercised choice, having been allocated a place at the school via a non-proximity criterion such as aptitude (or as the sibling of a child who gained a place via an aptitude criterion), thereby displacing pupils who live nearer to the school than they do. There is some evidence for this phenomenon in the data: $23 \%$ of the unexplained mobility pupils are attending foundation schools, versus $18 \%$ of the population and West et al. (2004) note that foundation schools are more likely to have selective admissions criteria than community comprehensives.

6. Displacement due to other's choice. If we believe that choice with displacement explains a significant proportion of this unexplained sorting, then we should expect a significant number of pupils to be not attending their (non-faith comprehensive) proximity school because they are rejected in favour of pupils who live further away from the school than they do, but who gain places on non-proximity criteria. 


\section{School segregation and post-residential sorting}

In this dataset, the weighted mean school segregation in LEAs, measured by the dissimilarity index, is 0.29 by FSM and 0.27 by top $20 \%$ ability. The level of school segregation differs substantially by LEA, as shown in Figure 3.

The regressions of LEA level school segregation on a set of school type variables in Table 4 shows that higher levels of school segregation are associated with greater proportions of pupils educated at grammar and VA schools (this identifies the possible effect of these schools without endogenous residential sorting confounding estimates, but is not a causal impact since the supply of school places is not explicitly modelled). Foundation schools are also associated with segregation by ability, but not FSM segregation in this sample. As with all regressions reported in this study, explanatory variables explain a relatively low proportion of variability in FSM segregation and a high proportion of variability in ability segregation. We cannot know whether this is due to the poorness of FSM as a proxy for social disadvantage, or whether school types have a clearer, more direct effect on ability sorting. 
Almost all LEAs have lower school segregation in the simulation proximity allocation of pupils to schools ( seg $^{\text {prox I }}$ ), the values of which directly result from residential segregation. This is an important finding since it cannot easily be reconciled with the suggestion that low income families are the principal beneficiaries of policies that reduce the role of residential location in school admissions.

Figure 4 maps the distribution of $\operatorname{seg}^{\text {real }}$ and $\mathrm{seg}^{\text {prox I }}$ in LEAs by FSM and top ability. The proximity segregation distribution represents the best possible reduction in school segregation by instituting a proximity policy. Overall, the weighted mean level of post-residential sorting is 0.05 (s.d. 0.04 ) by FSM and 0.11 (s.d. 0.12) by top ability. In both cases, segregation under the proximity allocation is typically lower. However, several LEAs have a lower calculated segregation between schools currently than in the proximity allocation, i.e. post-residential sorting is less than zero. This is most likely to be because large numbers of pupils are crossing LEA boundaries and so the calculation of segregation contains different pupils in each instance, i.e. the LEA is not the valid market. Alternatively, whether by chance or design, these LEAs have catchment areas drawn around 
schools that do not reflect strict proximity well and result in lower segregation.

\section{Insert figure 4 about here}

\section{Explaining levels of post-residential sorting}

There is a positive and significant correlation between levels of mobility in an LEA and post-residential sorting by FSM and ability. These correlations, shown in Figure 5, are $0.48,0.56$ and 0.62 for FSM, top ability and low ability, respectively. The outliers by top ability post-residential sorting are areas with grammar schools.

Insert figure 5 about here

Table 5 shows that LEAs with greater proportions of voluntary-aided, foundation or grammar schools have higher levels of post-residential ability and FSM sorting. Not surprisingly, the effect of grammar schools on top ability sorting is very high indeed: where grammar schools in an LEA educate $25 \%$ of the pupils, they contribute to a 0.35 unit increase in top ability post-residential sorting. VA and foundation schools control their 
own admissions, yet their typical effect on school sorting is different. VA non-grammar schools contribute to higher levels of FSM, top ability and bottom ability post-residential sorting than foundation non-grammar schools. All these findings are robust to the exclusion of London LEAs from the regressions. There is relatively weak evidence that post-residential sorting is lower in areas of high unemployment.

\section{Insert table 5 about here}

We can see that as pupils succeed in attending a non-proximity school this mobility raises school segregation relative to residential (or the proximity) segregation. We can use the proximity allocation to show that pupils who are not eligible for FSM are more likely to benefit from current sorting than FSM pupils, where 'benefit' is defined to mean they improve their peer group relative to the proximity allocation. Pupils who remain in the same school following the simulation may not have mobility, but this does not mean they do not benefit from sorting. We can say they will benefit if the choice policies produce an improved peer group at the school they currently attend.

One way to illustrate the peer group of a school is as the proportion of pupils eligible for FSM in the real data and Proximity I. Table 6 shows the 
change in the FSM peer group experienced by FSM and NONFSM pupils as a result of current mobility. $61 \%$ of FSM pupils are worse off in terms of their peer group under current sorting, compared to a proximity allocation. Just $13 \%$ of FSM pupils have mobility that results in them improving their peer group. By contrast, half of the pupils not eligible for FSM have a better peer group under current sorting (and some have a considerably better peer group, which is why more than $50 \%$ of pupils are worse off in the proximity allocation overall).

Insert table 6 about here

School segregation is said to matter because it creates inequalities in the school peer group experienced by children from different backgrounds. Standard estimates of the size of the peer group effect suggest a one s.d. improvement in a child's peer group leads to around a 0.1 s.d. in that child's achievement (see Ammermueller \& Pischke, 2006, for a recent summary). The proximity simulations suggest that the typical child currently experiencing a relatively poor peer group (one s.d. below the mean) would see this improve somewhat under a proximity allocation to around 0.57 s.d. below the mean peer group. Though this is a meaningful improvement in peer group and therefore predictive educational outcomes for the child, it 
would be wrong to claim that neighbourhood schooling offers a magic bullet for lowering social class inequalities in achievement.

\section{Post-1988 mobility and post-residential sorting}

The prediction of UK school choice researchers has been that the policies introduced since 1988 will increase pupil mobility and that this will in turn produce greater school segregation. Two simulations - Proximity II and III - can separate mobility likely to have existed pre-1988 from potentially newer mobility. Proximity III allows grammar and VA schools to keep existing pupils (to identify the post-residential sorting attributable to these schools) and Proximity II separates the contribution of VA schools to postresidential sorting by allowing only grammar schools to keep existing pupils.

Figure 6 shows that mobility caused by grammar and VA schools can explain most of the post-residential sorting of pupils by ability, but they explain little of the total FSM post-residential sorting.

Insert figure 6 about here

The weighted mean value of post-residential sorting that might be attributable to the post-1988 choice policies is 0.03 for each of FSM, top ability and low ability segregation. This is quite a low figure, but it varies 
between areas: it is as high as 0.20 in Haringey (by FSM); and 0.28 in Wandsworth (by high ability). Unfortunately this dataset is unsuccessful at explaining the between-LEA variability in this measure; detailed admissions policies information (not currently available from DfES) would seem the best route to understanding the effects of post-1988 choice policies more fully.

In this study the VA and foundation comprehensive schools have consistently been associated with greater school segregation and this is consistent with the surveys of West et al. (2004) who suggest that many of these schools have admissions policies that enable 'cream-skimming' of higher ability or social class pupils. By comparing a school's intake to its potential intake if it admitted the pupils closest to the school, ${ }^{15}$ an index of 'cream-skimming' is constructed as:

1. the FSM proportion currently at school divided by the FSM proportion of a proximity-based intake;

2. the top ability proportion currently at school divided by the top ability proportion of a proximity-based intake;

3. the low ability proportion currently at school divided by the low ability proportion of a proximity-based intake;

4. the mean ability of pupils currently at school divided by the mean ability of a proximity-based intake. 
The ratio is used to identify the top $10 \%$ of comprehensives on each creamskimming measure above. The choice of $10 \%$ is somewhat arbitrary, but this approach should only be used to identify the schools with a very high disparity in intake, relative to a proximity intake, since it cannot identify schools that are cream-skimming the middle layer of pupils, i.e. where they lose the most able pupils in their catchment to another school, but take moderately high ability pupils from other school's catchment areas. We could also risk labelling a school as 'cream-skimming' when in fact their current intake was slightly superior to proximity via the chance historical construction of catchment areas.

Table 7 shows us that many schools that control their admissions are 'cream-skimming' to increase their proportion of pupils of higher ability, or alternatively limit the proportion of their pupils who are low ability or from low income families. The dataset does not contain admissions criteria so we do not know whether cream-skimming can entirely be explained by explicit ability selection criteria, or whether more covert selection is taking place. This cream-skimming analysis is also consistent with the results from all earlier analysis in this study, which has emphasised that the role of VA faith schools in producing post-residential sorting is far greater than for foundation schools. VA schools appear to be responsible for well over half of all cream-skimming identified here, yet they make-up just $17 \%$ of comprehensive secondary schools. 
By contrast, LEA-controlled schools rarely appear to be cream-skimming, though it is notable that around one in ten voluntary-controlled schools schools of religious character but where the LEA determines admissions contain a much lower than expected FSM proportion. Can we use this finding to suggest that religious criteria are always likely to produce social stratification, but should not produce ability stratification provided a school is not covertly cream-skimming? This finding points to the need to explore why FSM pupils have been relatively unsuccessful at accessing their local faith schools, even where it is a non-admissions controlling school. Are they less likely to want a religious education for their child, or simply less able to demonstrate their commitment to a specific church?

Insert table 7 about here

\section{Discussion}

This study has sought to show that we can improve our understanding of the impact of school choice policies on student sorting via simulations that reallocate pupils to secondary schools strictly on the basis of proximity by exploiting the availability of pupil postcodes. This is a new (and therefore imperfect) technique and has not been attempted using NPD before. There 
are many routes to improving the simulations: for example, via consideration of each school's relevant geographical 'market'; by accounting directly for partial ability selection by comprehensives in the simulation; through repetition over several years to understand the changing role of the housing market; and by accounting for the part of the endogenous residential sorting that takes place between the ages of 5 and 11 as more years of pupil-level data become available.

Though half the pupils in the study do not actually attend their proximity allocation school, much of this can be likely attributed to the shape of catchment areas and the presence of grammar and VA schools (i.e. pre-1988 mobility). This study estimates that mobility between non-faith comprehensive schools is likely to involve no more than one in five pupils in England.

Pupil mobility results from the combination of both the choice to attend a non-proximity school and the displacement of local pupils by their proximity school and, if successfully exercised, naturally means longer journeys to school. The proximity allocation indicates that the typical journey currently made by a pupil is $60 \%$ longer than the minimum necessary. In fact, over 5 million kilometres ${ }^{16}$ of additional travel is made by 11-16 year olds every school day, either because parents are choosing not to send their child to the local school, or because the local school is choosing not to give the child a place. This raises important efficiency 
issues that are little discussed in the literature. We should not assume that a parent incorporates the external costs of pollution and congestion, even if they rationally decide that a longer journey (with the associated time and money cost for parent and child) is warranted by the 'superior' education at the end of the journey. Furthermore, if school places are highly constrained and proximity is not the sole allocation rule, one parent's rational choice to access a 'superior' education farther away from home may force a pupil local to the school to make a longer journey to an 'inferior' one.

The simulations show that FSM and ability segregation is almost always lower in the proximity counterfactual than in the actual data, confirming that where pupils are sorting themselves into a non-proximity school, it does tend to increase social and ability segregation between schools, relative to underlying residential segregation. This is contrary to the suggestion that choice policies are likely to disproportionately benefit low income families because they were previously unable to afford homes close to popular schools, thus lowering school segregation (e.g. Burgess et al., 2005; Hoxby, 2003). In England we did not start from a position of complete residential stratification, and in addition we have given schools both the means and the motivation to recruit pupils with above average ability and those with fewer problems. In this dataset we find comprehensives that have a pupil intake of considerably superior ability and social status to the pupils living closest to the school are overwhelmingly VA and (to a less extent) foundation schools. 
We cannot say whether this can solely be attributed to the overt and covert 'cream-skimming' of more desirable pupils, or whether differential school choice strategies and preferences by social class also play a significant role.

Unfortunately, we cannot use these findings to predict the size of the effect that removing discretion over admissions from grammar, VA and foundation schools and forcing a strict proximity allocation would have on school segregation because this model cannot identify the magnitude of the endogeneity of residential sorting. We can say that a proximity allocation has the potential to lower school segregation by the amount that is postresidential sorting, and the size of this potential reduction is greatest in areas with grammar, VA and foundation schools and higher population density areas. However, we do not know the extent to which residential segregation will rise in any one area to offset this potential fall, so post-residential sorting should be interpreted as the maximum possible reduction resulting from a proximity allocation. It is noteable, though, that areas with grammar, VA and foundation schools do not currently have lower residential segregation than areas where all schools operate catchment areas.

About two-thirds of LEAs have a level of post-residential FSM sorting that is lower than 0.05 , once segregation directly attributable to grammar and VA schools is accounted for. Though the simulations do measure significant mobility between non-faith comprehensives in these particular LEAs, it would be wiser to attribute this to the inability of the simulation to 
capture the shape of traditional catchment areas for schools than it would be to use this to suggest that these parts of the UK are indisputably achieving choice without greater school segregation. Indeed post-residential FSM sorting that might be associated with post-1988 policies is only a weighted mean average 0.03 across LEAs. This very low figure might explain why time-series of school segregation reveal so little change over time on a national basis. If policy makers genuinely wish to improve equality of educational opportunity in England, this study suggests they should look closer at the continuing role of grammar schools, voluntary-aided faith schools and, most of all, of the proximity oversubscription criterion in producing socially segregated secondary schools. 


\section{Notes}

${ }^{1} 7 \%$ of this year group transferred to secondary school at the end of year 7 or year 8

${ }^{2}$ There is some evidence that a pupil's probability of apply for FSM eligibility status depends, in part, on the culture of the school. This is discussed in Croxford (2000) and Shuttleworth (1995).

${ }^{3}$ In this study, references to community schools will always include voluntary-controlled schools since they make up just $2.9 \%$ of the schools in the sample and do not control their own admissions.

${ }^{4}$ Spare capacity in the LEA was also tested but never significant, so is not reported here.

${ }^{5}$ Population density is used as a proxy for the size of the parent's choice set. Alternatives such as average number of competitor schools within a certain radius (Levacic, 2004) or drive-time (Burgess et al., 2006) are relatively highly correlated at LEA level with average population density.

${ }^{6}$ The simulations retain single sex schools since gender is considered a fixed non-SES characteristic and so to avoid an upward bias on the effect of population density on mobility levels and a downward bias in the effect on sorting.

${ }^{7}$ Because of the need to exclude certain pupils from the allocation process, e.g. borders, the $\%$ capacity utilisation for 2000 is first calculated on the basis on total pupils at school. Where it is greater than $100 \%$, it is reset to $100 \%$. Simulation school capacity = pupils currently at school who are in simulation / \% capacity utilisation.

${ }^{8}$ The capacity constraint is significant in the simulation to the extent that if every pupil were allocated to their nearest school, $41 \%$ of schools would exceed their current capacity. 
Furthermore, if every school is filled to its current size but on the basis of proximity, 23\% of pupils are allocated to more than one school and $27 \%$ of pupils are not allocated at all.

${ }^{10}$ Many alternative specifications were tested, but do not alter the substantive findings of this report.

${ }^{11}$ For example, 449 pupils would be required to travel more than 5 times their current journey distance; 730 pupils would be required to travel over $10 \mathrm{~km}$ (though for some this is their nearest school).

${ }^{12}$ Alternative specifications of all regressions were tested using 105 areas created by combining LEAs where there are significant cross-LEA movements, but did not alter the substantive findings. Results are available from author for this specification of the model.

${ }^{15}$ This allocation mechanism is different to others in this study since pupils can be allocation to more than one school. All grammar schools and grammar school pupils are excluded from the allocation.

${ }^{16} 1.4$ million $\mathrm{km}$ total distance to school in real data versus 0.9 million $\mathrm{km}$ in proximity allocation. Difference of 0.5 million $\mathrm{km}$ is multiplied by 2 to incorporate the return journey and multiplied by 5 for the 5 year groups. 


\section{References}

Allen, R., \& Vignoles, A. (2006). What should an index of school segregation measure? CEE Discussion paper, available at http://cee.lse.ac.uk/pubs/default.asp.

Ammermueller, A. \& Pischke, J. Peer Effects in European Primary Schools: Evidence from PIRLS. CEE Discussion paper, available at http://cee.lse.ac.uk/pubs/default.asp

Black, S. E. (1999). Do better schools matter? Parental valuation of elementary education. Quarterly Journal of Economics, 114(2), 577-599.

Burgess, S., McConnell, B., Propper, C., \& Wilson, D. (2006). The impact of school choice on sorting by ability and socio-economic factors in English secondary education, in Woessmann, L. and Peterson, P. (eds) Schools and the Equal Opportunity Problem. Cambridge, MA: MIT Press

Burgess, S., Propper, C., \& Wilson, D. (2005). Will more choice improve outcomes in education and health care? The evidence from economic research. Bristol: CMPO, University of Bristol.

Cortese, C. F., Falk, R. F., \& Cohen, J. K. (1976). Further considerations on the methodological analysis of segregation indices. American Sociological Review, 41, 630-637.

Croxford, L. (2000). Is free-meal entitlement a valid measure of school intake characteristics? Educational Research and Evaluation, 6(4), 317-335.

Department for Education and Employment. (1999). Code of practice on school admissions. London: HMSO

Feinstein, L., \& Symons, J. (1999). Attainment in secondary school. Oxford Economic Papers, 51(2), 300-321.

Fitz, J., Taylor, C., Gorard, S., \& White, P. (2001). Local education authorities and the regulation of educational markets: Four case studies. Cardiff: Cardiff University School of Social Sciences.

Gewirtz, S., Ball, S., \& Bowe, R. (1995). Markets, choice and equity in education. Buckingham: Open University Press.

Gibbons, S., \& Machin, S. (2003). Valuing English primary schools. Journal of Urban Economics, 53, 197-219.

Gibbons, S., \& Machin, S. (2006). Paying for primary schools: Admissions constraints, school popularity or congestion? Economic Journal, 116

Glennerster, H. (1991). Quasi-markets and education. Economic Journal, 101, 12681271.

Goldstein, H., \& Noden, P. (2003). Modelling social segregation. Oxford Review of Education, 29, 225-237.

Gorard, S., Taylor, C., \& Fitz, J. (2003). Schools, markets and choice policies. London: RoutledgeFalmer.

Hastings, J. S., Kane, T. J., \& Steiger, D. O. (2005). Parental preferences and school competition: Evidence from a public school choice program (Working Paper No. 11805). Cambridge, Mass.: National Bureau of Economic Research. 
Hoxby, C. M. (2003). Introduction. In C. M. Hoxby (Ed.), The economics of school choice. Chicago: The University of Chicago Press.

Hutchens, R. M. (2004). One measure of segregation. International Economic Review, 45(2), 555-578.

Jowett, S. (1995). Allocating secondary school places: A study of policy and practice. Slough: National Foundation for Educational Research.

Ladd, H. F. (2002). School vouchers: A critical view. Journal of Economic Perspectives, 16(4), 3-24.

Leech, D., \& Campos, E. (2001). 'Is comprehensive education really free? A case study of the effects of secondary school admissions policies on house prices in one local area' (Warwick Economic Research Papers, No. 581): Warwick University.

Levačić, R. (2004). Competition and the performance of English secondary schools: Further evidence. Education Economics, 12(2).

Levačić, R., Jenkins, A., Vignoles, A., Steele, F., \& Allen, R. (2005). Estimating the relationship between school resources and pupil attainment at Key Stage 3. DfES Research Report 679, available at www.dfes.gov.uk/research/data/uploadfiles/RR679.pdf

Mayet, G. (1996). Admissions to schools: A study of local education authorities. In R. Glatter, P. A. Woods \& C. Bagley (Eds.), Choice and diversity in schooling: Perspectives and prospects. London: Routledge.

Noden, P. (2000). Rediscovering the impact of marketisation: Dimensions of social segregation in England's secondary schools, 1994-1999. British Journal of Sociology of Education, 21(3), 371-390.

Parsons, E., Chalkley, B., \& Jones, A. (2000). School catchments and pupil movements: A case study in parental choice. Educational Studies, 26(1).

Robertson, D., \& Symons, J. (2003). Do peer groups matter? Peer group versus schooling effects on academic attainment. Economica, 70(277), 31-53.

Roth, A. E. (1984). The evolution of the labor market for medican interns and residents: A case study in game theory. Journal of Political Economy, Y2(6).

Select Committee for Education \& Skills. (2005). Fifth report of session 2004-05 (secondary education) (Vol. Appendix I).

Shuttleworth, I. (1995). The relationship between social deprivation, as measured by individual free school meal eligibility, and educational attainment at GCSE in northern ireland: A preliminary investigation. British Educational Research Journal, 21(4), 487-504.

Waslander, S., \& Thrupp, M. (1995). Choice, competition and segregation: An empirical analysis of a New Zealand secondary school market. Journal of Education Policy, 10(1), 1-26.

West, A., Hind, A., \& Pennell, H. (2004). School admissions and 'selection' in comprehensive schools: Policy and practice. Oxford Review of Education, 30(3), 347-369. 
West, A., \& Pennell, H. (2003). Underachievement in schools. London: RoutledgeFalmer.

Willms, J., \& Echols, F. (1992). Alert and inert clients: The Scottish experience of parental choice of schools. Economics of Education Review, 11(4), 339-359.

Zanten, A. van (1996). Market trends and the French school system: Overt policy, hidden strategies, actual changes. Oxford Studies in Comparative Education, 6, 63-76.

Zimmer, R. W., \& Toma, E. F. (2000). Peer effects in private schools and public schools across countries. Journal of Policy Analysis and Management, 19(1), 75-92.

Zoloth, B. (1976). Alternative measures of school segregation. Land Economics, 52, 278-298. 


\section{Tables and Figures}

Table 1: Summary of key variables in dataset

Table 2: Summary statistics for allocation procedure

Table 3: Association between the quasi-market and level of mobility

Table 4: Association between school segregation and school types in LEA

Table 5: Results from post-residential sorting regression

Table 6: Gains from mobility as measured by change in FSM peer group

Table 7: Cream-skimming by comprehensive schools

Figure 1: Distribution of mobility levels across LEAs

Figure 2: Understanding why pupils do not attend their proximity school

Figure 3: School segregation in English LEAs

Figure 4: Current school versus Proximity I segregation

Figure 5: Relationship between pupil mobility and post-residential sorting

Figure 6: Sources of post-residential sorting 
Table 1: Summary of key variables in dataset

\begin{tabular}{|c|c|c|c|c|c|}
\hline & Description & Mean & S.D. & Min & Max \\
\hline & Number of pupils in LEA & 5,139 & 3,559 & 361 & 13,157 \\
\hline & Number of schools in LEA & 34 & 25 & 3 & 101 \\
\hline & Average population density in LEA & 0 & 1 & -0.77 & 5.82 \\
\hline & $\begin{array}{r}\text { Proportion of pupils in LEA currently educated at } \\
\text { grammar schools }\end{array}$ & $4 \%$ & $9 \%$ & $0 \%$ & $42 \%$ \\
\hline & $\begin{array}{r}\text { Proportion of pupils in LEA currently educated at } \\
\text { voluntary aided comprehensive schools }\end{array}$ & $14 \%$ & $10 \%$ & $0 \%$ & $65 \%$ \\
\hline & $\begin{array}{r}\text { Proportion of pupils in LEA currently educated at } \\
\text { foundation comprehensive schools }\end{array}$ & $16 \%$ & $19 \%$ & $0 \%$ & $100 \%$ \\
\hline & Proportion of pupils eligible for FSM & $13 \%$ & $9 \%$ & $3 \%$ & $64 \%$ \\
\hline & Proportion of lone parent families & $7 \%$ & $1 \%$ & $5 \%$ & $14 \%$ \\
\hline & Proportion of families with no parent in work & $13 \%$ & $6 \%$ & $4 \%$ & $49 \%$ \\
\hline Mobil & $\begin{array}{r}\text { ity }=\text { proportion of pupils in simulation that do not } \\
\text { remain in current school }\end{array}$ & $52 \%$ & $14 \%$ & $15 \%$ & $86 \%$ \\
\hline Prop & $\begin{array}{r}\text { ortion of LEA's median pupil's real journey that is } \\
\text { made in simulation }\end{array}$ & $64 \%$ & $12 \%$ & $31 \%$ & $95 \%$ \\
\hline & Segregation (D) in real data & 0.29 & 0.07 & 0.13 & 0.54 \\
\hline & Segregation (D) in Simulation I & 0.24 & 0.06 & 0.07 & 0.45 \\
\hline$\sum_{S=\infty}^{\infty}$ & Post-residential sorting ( $\left.\mathrm{seg}^{\text {real }}-\mathrm{seg}^{\text {prox I }}\right)$ & 0.05 & 0.05 & -0.17 & 0.38 \\
\hline & $\begin{array}{l}\text { Post-residential sorting NOT due to grammars } \\
\left.\text { and VA ( } \mathrm{seg}^{\text {real }} \text {-seg }^{\text {prox III }}\right)\end{array}$ & 0.03 & 0.04 & -0.11 & 0.20 \\
\hline & Segregation (D) in real data & 0.27 & 0.14 & 0.06 & 0.71 \\
\hline 20 & Segregation (D) in Simulation I & 0.16 & 0.03 & 0.04 & 0.27 \\
\hline กิ : & Post-residential sorting $\left(\mathrm{seg}^{\text {real }}-\mathrm{seg}^{\text {prox I }}\right)$ & 0.11 & 0.14 & -0.05 & 0.58 \\
\hline$\overline{0} \frac{\pi}{\pi}$ & $\begin{array}{l}\text { Post-residential sorting NOT due to grammars } \\
\left.\text { and VA ( } \text { seg }^{\text {real }}-\text {-seg }^{\text {prox III }}\right)\end{array}$ & 0.03 & 0.03 & -0.05 & 0.28 \\
\hline & Segregation (D) in real data & 0.23 & 0.08 & 0.09 & 0.51 \\
\hline 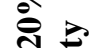 & Segregation (D) in Simulation I & 0.16 & 0.04 & 0.01 & 0.29 \\
\hline $\bar{n}$ & Post-residential sorting ( seg $^{\text {real }}-$ seg $\left.^{\text {prox I }}\right)$ & 0.07 & 0.07 & -0.05 & 0.40 \\
\hline$\overline{0}$ & $\begin{array}{l}\text { Post-residential sorting NOT due to grammars } \\
\left.\text { and VA (seg }{ }^{\text {real }} \text {-seg }^{\text {prox III }}\right)\end{array}$ & 0.03 & 0.03 & -0.04 & 0.22 \\
\hline & Segregation (ICC) in real data & 0.12 & 0.10 & 0.01 & 0.47 \\
\hline$\nexists \bar{\Xi}$ & Segregation (ICC) in Simulation I & 0.04 & 0.02 & 0.00 & 0.13 \\
\hline :气 & Post-residential sorting $\left(\mathrm{seg}^{\text {real }}-\mathrm{seg}^{\text {prox I }}\right)$ & 0.09 & 0.10 & -0.02 & 0.45 \\
\hline$\overline{0}$ & $\begin{array}{l}\text { Post-residential sorting NOT due to grammars } \\
\left.\text { and VA ( } \text { seg }^{\text {real }}{ }_{\text {-seg }}^{\text {prox III }}\right)\end{array}$ & 0.02 & 0.02 & -0.01 & 0.18 \\
\hline
\end{tabular}


Table 2: Summary statistics for proximity allocation procedure

\begin{tabular}{rrrrrr}
\hline Round & $\begin{array}{r}\text { Pupils } \\
\text { needing } \\
\text { places }\end{array}$ & $\begin{array}{r}\text { Pupils placed in } \\
\text { round }\end{array}$ & $\begin{array}{r}\text { Minimum } \\
\text { journey to } \\
\text { allocated } \\
\text { school }\end{array}$ & $\begin{array}{r}\text { Median } \\
\text { journey to } \\
\text { allocated } \\
\text { school }\end{array}$ & $\begin{array}{r}\text { Maximum } \\
\text { journey to } \\
\text { allocated } \\
\text { school }\end{array}$ \\
\hline 1 & 463,117 & $388,311(84 \%)$ & $0.0 \mathrm{~km}$ & $0.9 \mathrm{~km}$ & $38.8 \mathrm{~km}$ \\
2 & 74,806 & $47,107(63 \%)$ & $0.2 \mathrm{~km}$ & $2.4 \mathrm{~km}$ & $25.5 \mathrm{~km}$ \\
3 & 27,699 & $16,690(60 \%)$ & $1.0 \mathrm{~km}$ & $3.6 \mathrm{~km}$ & $35.9 \mathrm{~km}$ \\
4 & 11,009 & $6,619(60 \%)$ & $1.3 \mathrm{~km}$ & $5.2 \mathrm{~km}$ & $43.8 \mathrm{~km}$ \\
5 & 4,390 & $2,798(64 \%)$ & $2.5 \mathrm{~km}$ & $6.3 \mathrm{~km}$ & $44.7 \mathrm{~km}$ \\
6 & 1,592 & $802(50 \%)$ & $4.1 \mathrm{~km}$ & $7.4 \mathrm{~km}$ & $46.3 \mathrm{~km}$ \\
7 & 790 & $464(59 \%)$ & $6.2 \mathrm{~km}$ & $8.9 \mathrm{~km}$ & $82.2 \mathrm{~km}$ \\
8 & 326 & $256(79 \%)$ & $8.3 \mathrm{~km}$ & $13.3 \mathrm{~km}$ & $15.8 \mathrm{~km}$ \\
9 & 70 & $70(100 \%)$ & $13.0 \mathrm{~km}$ & $14.4 \mathrm{~km}$ & $16.1 \mathrm{~km}$ \\
\hline
\end{tabular}

Table 3: Association between the quasi-market and level of mobility

\begin{tabular}{|c|c|c|c|c|}
\hline $\begin{array}{l}\text { Dependent variable }= \\
\text { Number of observations }= \\
\text { Adj. R-squared }=\end{array}$ & \multicolumn{4}{|c|}{$\begin{array}{l}\text { mobility } \\
147, \text { weighted for number of pupils in LEA } \\
75 \%\end{array}$} \\
\hline & Coeff. & t-stat & $\mathbf{P}>|\mathbf{t}|$ & \\
\hline Proportion of pupils at grammar schools & 0.6999 & 10.43 & 0.001 & $* *$ \\
\hline Proportion of pupils at VA schools & 0.6147 & 8.31 & 0.001 & $* *$ \\
\hline Proportion of pupils at foundation schools & 0.0987 & 30.06 & 0.003 & $* *$ \\
\hline Population density & 0.0513 & 5.49 & 0.001 & $* *$ \\
\hline Proportion of lone parent families & 1.1384 & 1.82 & 0.071 & \\
\hline Proportion with no parent in work & 0.0831 & 0.53 & 0.594 & \\
\hline Constant & 0.2927 & 7.04 & 0.001 & $* *$ \\
\hline
\end{tabular}

Note: $*=$ sig. at $5 \% ; * *=$ sig. at $1 \%$.

Table 4: Association between school segregation and school types in LEA

Dependent variable $=$ seg $^{\text {real }}$.

No. of observations $=147$ (weighted for number of pupils in LEA)

\begin{tabular}{|c|c|c|c|c|}
\hline Adj. R-squared & $\begin{array}{c}\text { FSM (D) } \\
22 \%\end{array}$ & $\begin{array}{c}\text { Top ability (D) } \\
86 \%\end{array}$ & $\begin{array}{c}\text { Low ability (D) } \\
72 \%\end{array}$ & $\begin{array}{c}\text { Ability ICC } \\
89 \%\end{array}$ \\
\hline $\begin{array}{l}\text { Proportion of pupils at } \\
\text { grammar schools }\end{array}$ & $0.320(5.88) * *$ & $1.397(28.57) * *$ & $0.696(17.97) * *$ & $1.055(32.94) * *$ \\
\hline $\begin{array}{l}\text { Proportion of pupils at } \\
\text { VA schools }\end{array}$ & $0.206(3.43) \quad * *$ & $0.187(3.46) * *$ & $0.203(4.75) * *$ & $0.139(3.94) * *$ \\
\hline $\begin{array}{l}\text { Proportion of pupils at } \\
\text { foundation schools }\end{array}$ & $0.030(1.13)$ n.s. & $0.084(3.56) * *$ & $0.048(2.59) * *$ & $0.073(4.74) * *$ \\
\hline Population density & $-0.009(-1.25)$ n.s. & $0.003(0.41) n . s$. & $0.001(0.20) n . s$. & 0.002 (0.60) n.s. \\
\hline $\begin{array}{l}\text { Proportion of lone } \\
\text { parent families }\end{array}$ & $-0.080(-0.16)$ n.s. & $1.150(2.52) *$ & 0.505 ( 1.40$)$ n.s. & 0.420 ( 1.41$)$ n.s. \\
\hline $\begin{array}{l}\text { Proportion with no } \\
\text { parent in work }\end{array}$ & $-0.091(-0.72)$ & $-0.065(-0.57)$ n.s. & $-0.192(-2.13) *$ & $-0.050(-0.67)$ n.s. \\
\hline Constant & $0.258(7.65) * *$ & $0.101(3.34)$ n.s. & $0.155(6.48) * *$ & 0.025 ( 1.24$)$ n.s. \\
\hline
\end{tabular}


Table 5: Results from post-residential sorting regression

\begin{tabular}{|c|c|c|c|c|}
\hline $\begin{array}{l}\text { Dependent variable }= \\
\text { No. of observations }=\end{array}$ & $\begin{array}{l}\text { seg }^{\text {real }}-\text { seg }^{\text {prox } 1} \\
147 \text { (weighted for } 1\end{array}$ & mber of pupils in $\mathrm{L}$ & & \\
\hline & FSM & Top ability & Low ability & Ability ICC \\
\hline Adj. R squared & $33 \%$ & $90 \%$ & $82 \%$ & $92 \%$ \\
\hline $\begin{array}{l}\text { Proportion at grammar } \\
\text { schools }\end{array}$ & $0.215(5.56) * *$ & $1.400(33.35) * *$ & $0.686(23.29) * *$ & $1.059(39.14) * *$ \\
\hline Proportion at VA schools & $0.099(2.34) *$ & $0.159(3.43) * *$ & $0.162(4.98) * *$ & $0.133(4.47) * *$ \\
\hline $\begin{array}{l}\text { Proportion at foundation } \\
\text { schools }\end{array}$ & $0.045(2.42) *$ & $0.073(3.62) * *$ & $0.035(2.50) * *$ & $0.067(5.16) * *$ \\
\hline Population density & $0.015(2.76) * *$ & $0.024(4.05) * *$ & $0.021(5.12) * *$ & $0.012(3.14) * *$ \\
\hline $\begin{array}{l}\text { Proportion of lone parent } \\
\text { families }\end{array}$ & $-0.026(-0.07) n . s$. & $0.827(2.11) *$ & $0.171(0.62)$ n.s. & 0.282 ( 1.12$)$ n.s. \\
\hline $\begin{array}{l}\text { Proportion with no parent } \\
\text { in work }\end{array}$ & $-0.004(-0.04)$ n.s. & $-0.240(-2.46) *$ & $-0.208(-3.04) * *$ & $-0.094(-1.50)$ n.s. \\
\hline Constant & $0.022(0.92)$ n.s. & $-0.005(-0.22)$ n.s. & 0.033 ( 1.79$)$ n.s. & 0.005 ( 0.29) n.s. \\
\hline
\end{tabular}

Table 6: Gains from mobility as measured by change in FSM peer group

\begin{tabular}{lcc|cc}
\hline & \multicolumn{2}{c|}{$\begin{array}{c}\text { Worse peer group than under } \\
\text { proximity }\end{array}$} & Better peer group than under proximity \\
\hline & $\begin{array}{c}\text { \% in a different } \\
\text { school }\end{array}$ & $\begin{array}{c}\text { \% remaining in } \\
\text { the same school }\end{array}$ & $\begin{array}{c}\text { \% in a different } \\
\text { school }\end{array}$ & $\begin{array}{c}\text { \% remaining in } \\
\text { the same school }\end{array}$ \\
\hline Pupils eligible for FSM & $29.86 \%$ & $31.45 \%$ & $13.3 \%$ & $25.38 \%$ \\
$\begin{array}{l}\text { Pupils not eligible for } \\
\text { FSM }\end{array}$ & $29.16 \%$ & $20.86 \%$ & $19.62 \%$ & $30.36 \%$ \\
\hline
\end{tabular}

Table 7: Cream-skimming by comprehensive schools

Proportion of schools identified as 'cream-skimming'

\begin{tabular}{|c|c|c|c|c|c|c|}
\hline & 泀 & 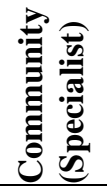 & 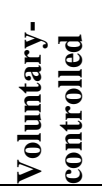 & 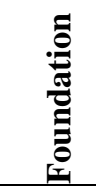 & 槖 & $\begin{array}{c}\text { Ratio value for } \\
\text { cream-skimming } \\
\text { schools }\end{array}$ \\
\hline by free-school meals & $4 \%$ & $5 \%$ & $11 \%$ & $13 \%$ & $30 \%$ & 0.00 to 0.55 \\
\hline by KS2 ability & $2 \%$ & $5 \%$ & $4 \%$ & $12 \%$ & $38 \%$ & 1.03 to 1.20 \\
\hline by lowest $20 \%$ ability & $3 \%$ & $5 \%$ & $3 \%$ & $12 \%$ & $36 \%$ & 0.00 to 0.66 \\
\hline by top $20 \%$ ability & $4 \%$ & $4 \%$ & $3 \%$ & $13 \%$ & $33 \%$ & 1.42 to 15.33 \\
\hline Number of schools & & & & & & \\
\hline
\end{tabular}

Note: Community (Specialist) identifies LEA controlled schools that were given Specialist status in or before 2000 (when these pupils entered secondary school). All Specialist schools could choose to select $10 \%$ of pupils by aptitude, though most did not. 
Figure 1: Distribution of mobility levels across LEAs

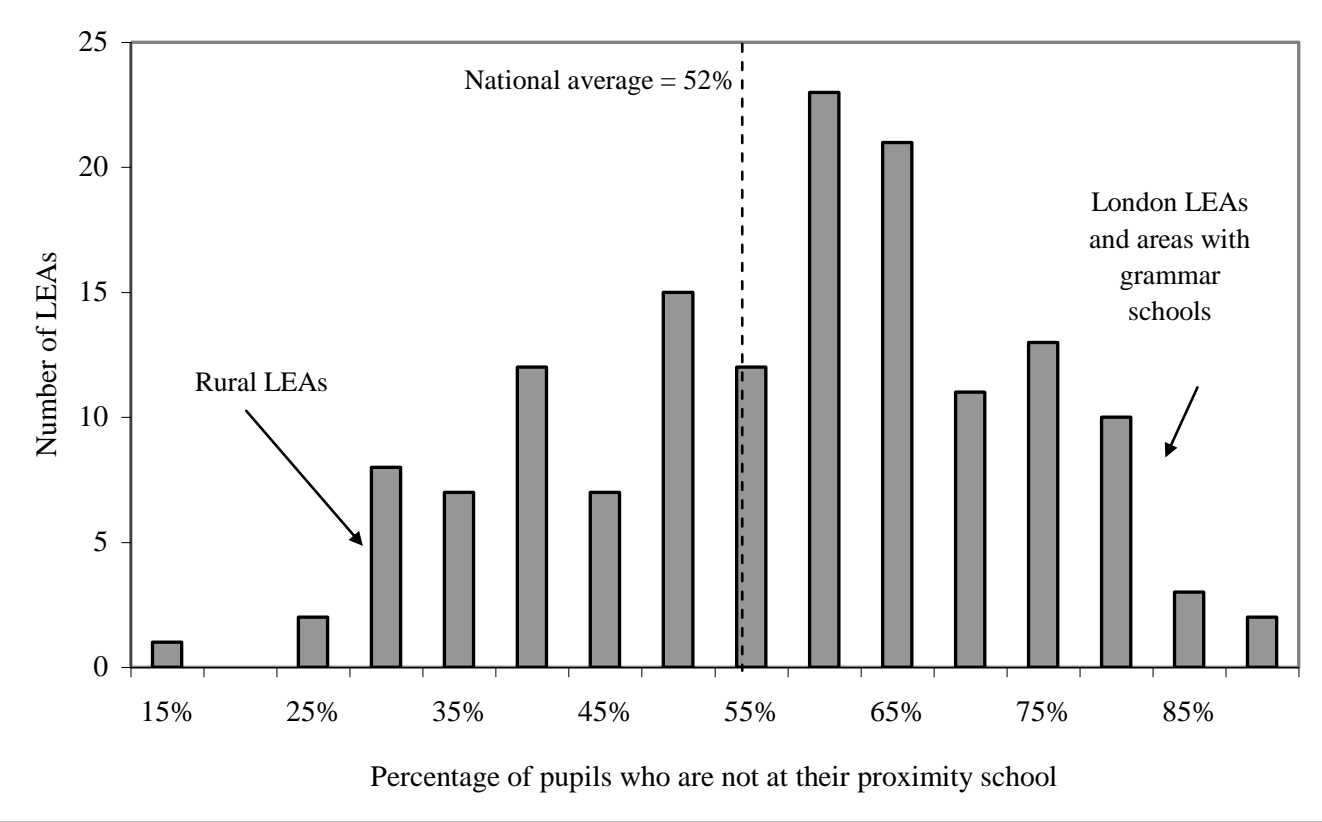

Figure 2: Understanding why pupils do not attend their proximity school

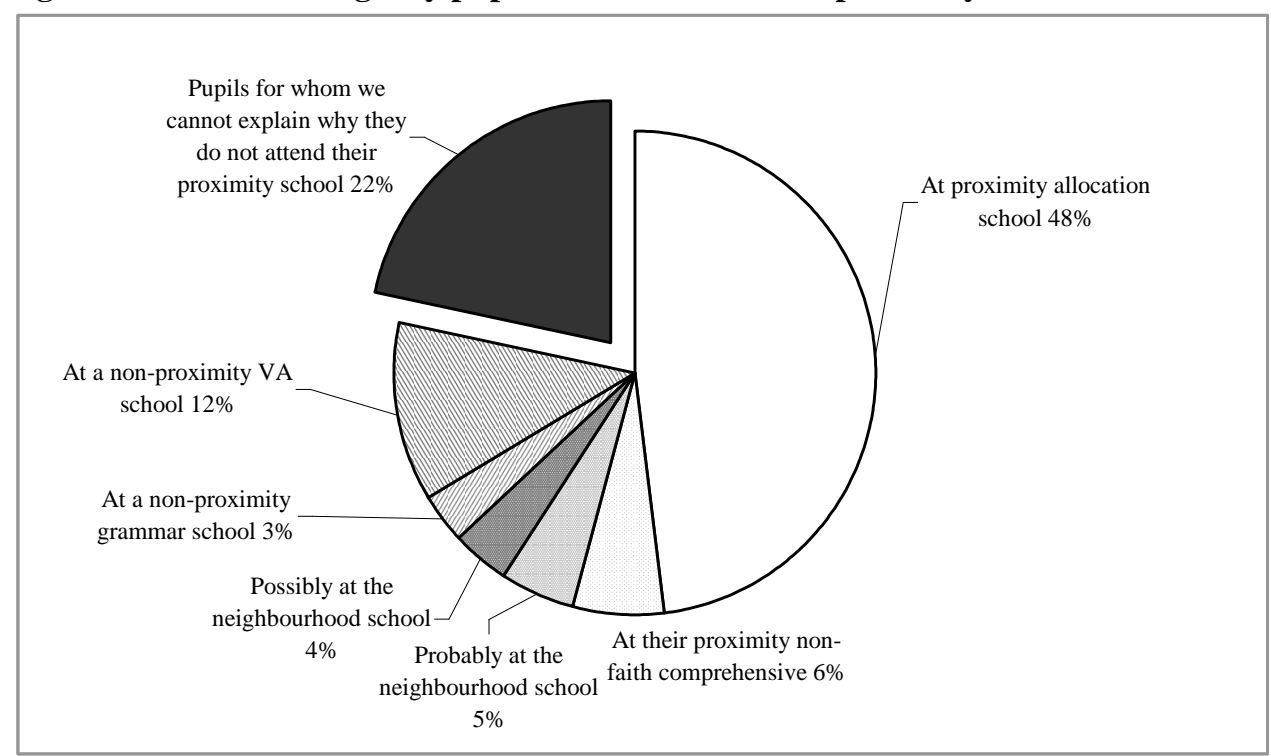


Figure 3: School segregation in English LEAs

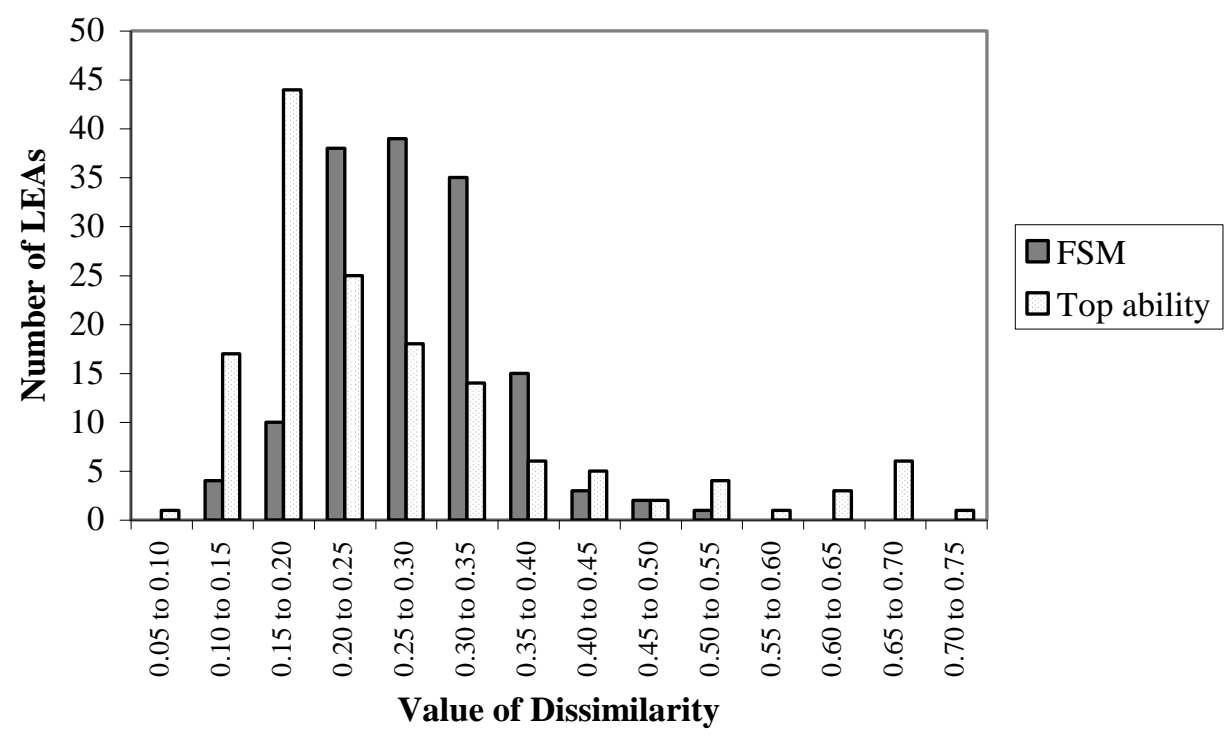

Figure 4: Current school versus Proximity I segregation
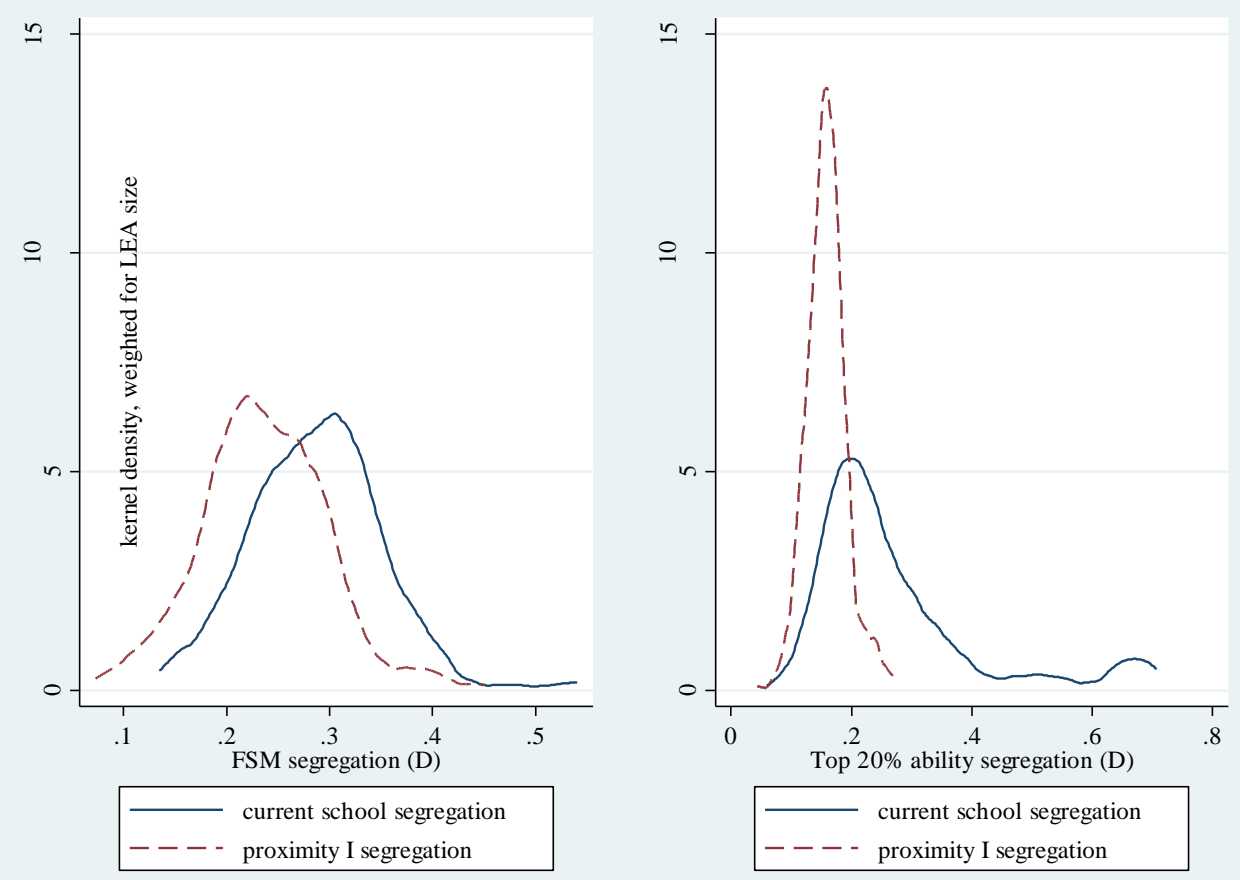
Figure 5: Relationship between pupil mobility and post-residential sorting
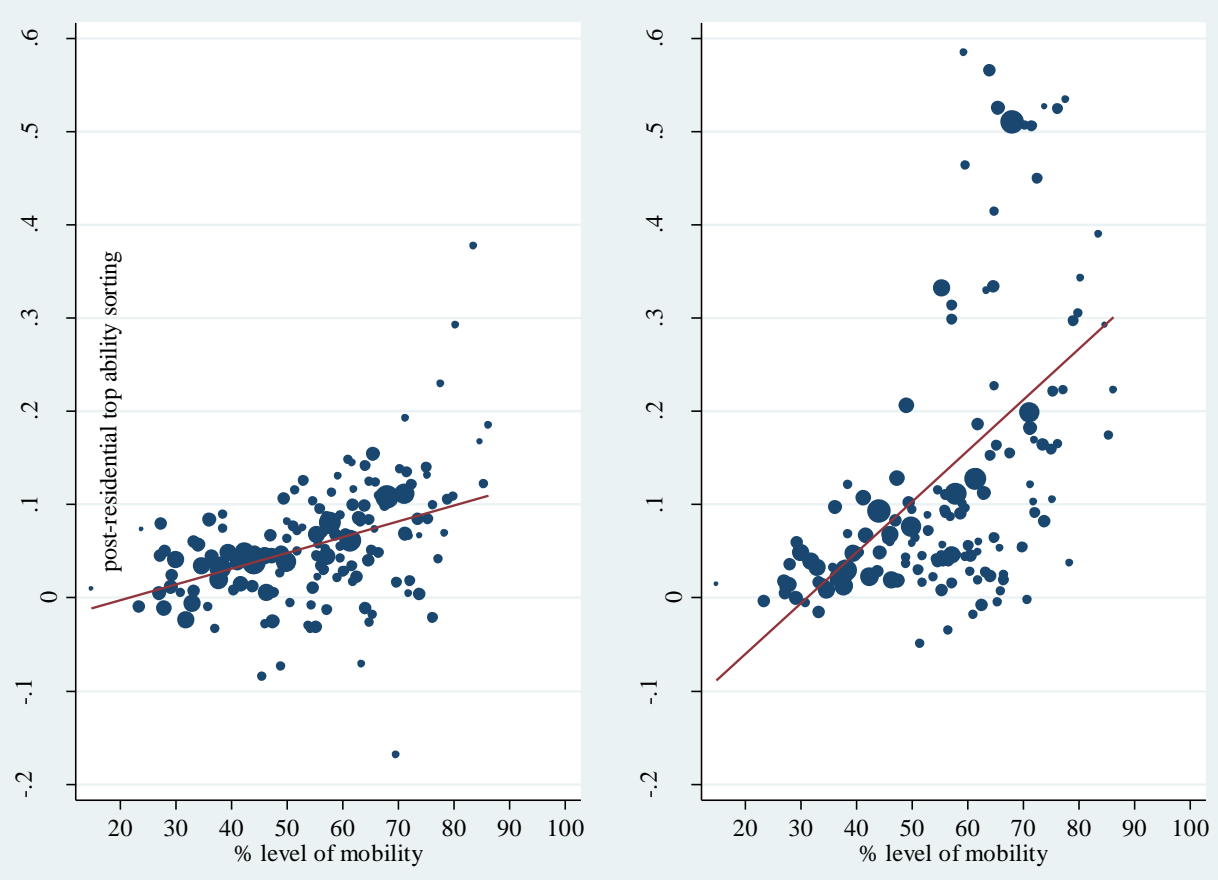

Figure 6: Sources of post-residential sorting

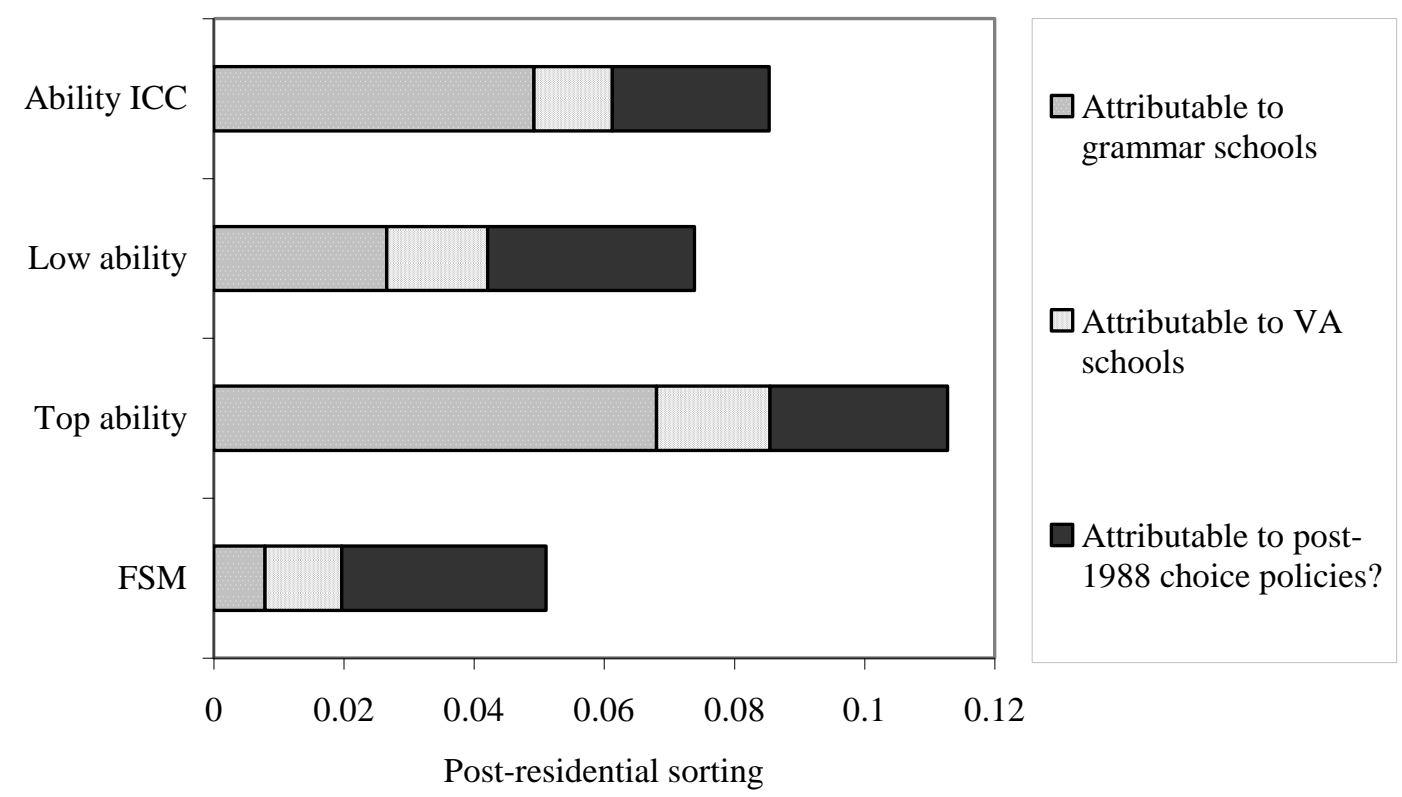

